\title{
APLIKASI REGRESI DATA PANEL DENGAN PENDEKATAN FIXED EFFECT MODEL (STUDI KASUS: PT PLN GIANYAR)
}

\author{
Ni Putu Anik Mas Ratnasari ${ }^{1}$, I Putu Eka Nila Kencana ${ }^{2}$, G. K. Gandhiadi ${ }^{3}$ \\ 1,2,3 Jurusan Matematika FMIPA Universitas Udayana, Bukit Jimbaran-Bali \\ e-mail: ${ }^{1}$ anic.aruka@gmail.com,2i.putu.enk@gmail.com, \\ ${ }^{3}$ gandhiadigk@yahoo.com
}

\begin{abstract}
Panel data regression has three approaches. One of these approaches is Fixed Effect Model (FEM). FEM is common estimated using Least Square Dummy Variable. The use of dummy variable in FEM is based on assumption that slope coefficients are constant but intercept varies over individuals. One of application of FEM is to find out motivation of employees at PT PLN Gianyar for non-outsourcing and outsourcing employees based on existence, relatedness, and growth. This research yields the following two models:

1. $M_{\text {ot }}$ non $_{i t}=-0,05+0,56 E X_{i t}$

2. Mot $_{\text {out }_{\text {it }}}=0,21-0,00 E X_{i t}+0,85 G R_{i t}$

with $67 \%$ motivation non-outsourcing employees represented by existenceand $73 \%$ motivation nonoutsourcing employees represented by existence and growth.
\end{abstract}

Keywords: Panel Data Regression, Fixed Effect Model, Motivation

\section{Pendahuluan}

Analisis regresi merupakan alat statistika yang memanfaatkan hubungan antara dua atau lebih variabel yang bersifat kuantitatif, sehingga salah satu variabel dapat diprediksi dari variabel lainnya. Salah satu pengembangan dari analisis regresi adalah regresi data panel. Ada beberapa keuntungan menggunakan regresi data panel, yaitu mampu mengontrol keheterogenan individual, dengan data cross-section diasumsikan homogen tanpa ada pengaruh lain yang masuk, misal waktu, sedangkan pada data time-series, data yang didapat akan berubah setiap periode waktu. Penggabungan dari kedua data ini dapat mengatasi masalah yang timbul karena penghilangan variabel; memberikan data yang lebih informatif; membangun dan menguji model yang lebih kompleks dibandingkan dengan mengunakan data time series atau cross-section murni karena data panel merupakan gabungan dari kedua studi ini; serta dapat meminimumkan bias yang terjadi bila mengelompokkan individu ke dalam kelompok yang lebih besar.

Regresi data panel memiliki tiga pendekatan, yaitu Common Effect Model (CEM), Fixed Effect Model (FEM), dan Random Effect Model (REM). FEM adalah model regresi data panel yang menggunakan variabel dummy untuk mengetahui perbedaan karakteristik, baik antarindividu maupun antarwaktu. Penerapan regresi data panel sebagai salah satu metode untuk mengetahui

\footnotetext{
${ }^{1}$ Mahasiswa Jurusan Matematika FMIPA Universitas Udayana

${ }^{2}$ Staf Pengajar Jurusan Matematika FMIPA Universitas Udayana
} 
perbedaan karakteristik dapat juga diterapkan pada kasus tenaga kerja.

Dewasa ini, banyak hal yang memengaruhi setiap orang untuk menjadi tenaga kerja, baik itu tenaga kerja nonoutsourcing, kontrak, ataupun outsourcing. Salah satu faktornya adalah adanya motivasi. Hal ini disebabkan karena motivasi merupakan dorongan yang timbul pada diri seseorang secara sadar ataupun tidak sadar untuk melakukan suatu tindakan dengan tujuan tertentu (Tim Penyusun Pusat Bahasa, 2012). Pada penelitian ini akan dilihat motivasi tenaga kerja non-outsourcing dan outsourcing di PT PLN Gianyar berdasarkan existence, relatedness, dan growth dengan pengertian dari masing-masing variabel yaitu existence adalah kebutuhan seseorang untuk mendapat pengakuan sebagai seorang manusia,baik di tengah masyarakat maupun perusahaan, relatednessadalah kebutuhan keterikatan antara seseorang dengan lingkungan sosial di sekitarnya, serta growth adalah kebutuhan yang berkaitan dengan pengembangan potensi diri seseorang sehingga menimbulkan penghargaan atas potensi yang dimiliki.

\section{Ulasan Pustaka}

\section{Regresi Data Panel}

Regresi data panel adalah regresi yang menggunakan data pengamatan terhadap satu atau lebih variabel pada suatu unit secara terus menerus selama beberapa periode waktu. Bentuk umum model regresi data panel adalah sebagai berikut (Hsiao, 2003):

$$
\boldsymbol{Y}_{i t}=\boldsymbol{\alpha}_{i t}^{*}+\boldsymbol{\beta}_{i t}^{T r} \boldsymbol{X}_{i t}+\boldsymbol{\mu}_{i t}
$$

dengan $\boldsymbol{Y}_{\boldsymbol{i t}}$ adalah pengamatan unit cross section ke- $i$ dan waktu ke- $t, \boldsymbol{\alpha}_{i t}^{*}$ adalah intersep; efek grup/individu dari unit cross section ke- $i$ dan waktu ke- $t, \quad X_{i t}^{T r}=$ $\left(X_{1 i t}, X_{2 i t}, \ldots, X_{K i t}\right)$ merupakan variabel bebas untuk unit cross section ke- $i$ dan waktu ke- $t, \boldsymbol{\beta}_{i t}^{\boldsymbol{T r}}=\left(\beta_{1}, \beta_{2}, \ldots, \beta_{K}\right)$ merupakan koefisien slope untuk semua unit, $\mu_{i t}$ adalah error regresi untuk unit cross section ke- $i$ dan waktu ke- $t, i=1,2, \ldots, N$ untuk unit cross section,t=1, 2, ..., T untuk waktu dan Tradalah simbol transpose.

Terdapat beberapa kemungkinan asumsi pada data panel, yaitu:

1. Intersep dan koefisien slope konstan sepanjang waktu dan individu serta error berbeda sepanjang waktu dan individu.

Modelnya adalah:

$$
\boldsymbol{Y}_{i t}=\alpha^{*}+\sum_{k=1}^{K} \boldsymbol{\beta}_{k}^{T r} \boldsymbol{X}_{k i t}+\boldsymbol{\mu}_{i t} \text {. }
$$

2. Koefisien slope konstan, tetapi intersep berbeda untuk semua individu. Modelnya adalah:

$$
\boldsymbol{Y}_{i t}=\alpha_{i}^{*}+\sum_{k=1}^{K} \beta_{k}^{T r} X_{k i t}+\mu_{i t}
$$

3. Koefisien slope konstan, tetapi intersep berbeda baik sepanjang waktu maupun antarindividu. Modelnya adalah:

$$
Y_{i t}=\alpha_{i t}^{*}+\sum_{k=1}^{K} \beta_{k}^{T r} X_{k i t}+\mu_{i t} .
$$

4. Intersep dan koefisien slope berbeda untuk semua individu. Modelnya adalah:

$$
\boldsymbol{Y}_{i t}=\alpha_{i}^{*}+\sum_{k=1}^{K} \beta_{k i}^{T r} X_{k i t}+\mu_{i t} .
$$

5. Intersep dan koefisien slope berbeda sepanjang waktu dan untuk semua individu. Modelnya adalah:

$$
Y_{i t}=\alpha_{i t}^{*}+\sum_{k=1}^{K} \beta_{k i t}^{T} X_{k i t}+\mu_{i t}
$$

\section{Fixed Effect Model}

Salah satu metode estimasi yang bisa digunakan dalam model regresi data panel adalah fixed effect model (FEM). Bentuk umum regresi data panel pada FEM adalah sebagai berikut:

$$
Y_{i t}=\alpha_{i}^{*}+\beta^{T r} X_{i t}+\mu_{i t}
$$

Indeks $i$ pada intersep menunjukkan bahwa intersep dari masing-masing unit crosssection berbeda-beda. Perbedaan ini disebabkan karena penggunaan variabel dummy untuk menjelaskan perbedaan intersep yang timbul antarindividu. Istilah FEM berasal dari kenyataan bahwa meskipun intersep $\alpha_{i}$ berbeda antarindividu namun intersep sama antarwaktu (time invariant) 
(Gujarati, 2004). Hal ini juga memberikan asumsi bahwa slope $\beta$ tetap sama antarindividu dan antarwaktu. Oleh karena itu persamaan di atas bisa ditulis menjadi:

$$
Y_{i t}=D \alpha_{i}^{*}+\beta^{T r} X_{i t}+\mu_{i t}
$$

Dengan $\boldsymbol{D}=\left[\begin{array}{llll}d_{1} & d_{2} & \ldots & d_{n}\end{array}\right]$ merupakan variabel dummy untuk unit ke-i (Greene, 2012). Penggunakaan variabel dummy inilah yang membuat estimasi pada FEM disebut Least Square Dummy Variabel (LSDV) model.

\section{MetodePenelitian}

Sumber data pada penelitian ini adalah data primer yang didapatkan dengan menyebarkan kuesioner di PT PLN Gianyar kepada 25 orang tenaga kerja nonoutsourcing dan 25 orang outsourcing yang bekerja minimal dari tahun 2010 sampai 2012. Variabel respon (Y) yang digunakan pada penelitian ini adalah motivasi yang dimiliki oleh tenaga kerjanon-outsourcing dan outsourcingserta variabel bebas yang digunakan yaitu existence $\left(X_{1}\right)$ yang indikatornnya gaji, lingkungan kerja, dan jaminan social; relatedness $\left(X_{2}\right)$ yang indikatornya komunikasi, supervisi, dan kelompok;serta growth $\left(X_{3}\right)$ yang indikatornya penghargaan, prestasi, dan tanggung jawab. Berikut uraian variabelvariabelnya pada tabel 1 .

Tabel 1. Variabel-Variabel Penelitian

\begin{tabular}{|c|c|c|c|c|c|}
\hline No & Variabel & Simbol & Indikator & Skala & Kategori \\
\hline 1. & Motivasi (Y) & Mot & & Interval & $0-3$ \\
\hline \multirow{3}{*}{2} & \multirow{3}{*}{ Existence $\left(X_{1}\right)$} & \multirow{3}{*}{ EX } & Gaji $\left(X_{11}\right)$ & Interval & $0-3$ \\
\hline & & & Lingkungan Kerja $\left(X_{12}\right)$ & Interval & $0-3$ \\
\hline & & & Jaminan Sosial $\left(X_{13}\right)$ & Interval & $0-3$ \\
\hline \multirow{3}{*}{3} & \multirow{3}{*}{$\begin{array}{l}\text { Relatedness } \\
\qquad\left(X_{2}\right)\end{array}$} & \multirow{3}{*}{ RE } & Komunikasi $\left(X_{21}\right)$ & Interval & $0-3$ \\
\hline & & & Supervisi $\left(X_{22}\right)$ & Interval & $0-3$ \\
\hline & & & Kelompok $\left(X_{23}\right)$ & Interval & $0-3$ \\
\hline \multirow{3}{*}{4} & \multirow{3}{*}{ Growth $\left(X_{3}\right)$} & \multirow{3}{*}{ GR } & Penghargaan $\left(X_{31}\right)$ & Interval & $0-3$ \\
\hline & & & Prestasi $\left(X_{32}\right)$ & Interval & $0-3$ \\
\hline & & & Tanggung Jawab $\left(X_{33}\right)$ & Interval & $0-3$ \\
\hline 5 & $\begin{array}{c}\text { Tenaga Kerja } \\
\qquad\left(X_{4}\right)\end{array}$ & & & Nominal & $\begin{array}{l}0=\text { Non }- \\
\text { Outsourcing } \\
1= \\
\text { Outsourcing }\end{array}$ \\
\hline
\end{tabular}

Langkah-langkah pada penelitian ini adalah sebagai berikut: (1) menyebarkan kuesioner kepada seluruh tenaga kerja, baik tenaga kerja non-outsourcing dan outsourcing di PT PLN Gianyar, (2) uji validitas, reliabilitas, dan confirmatory factor analysis, (3) statistik deskriptif, (4) uji asumsi klasik, meliputi uji kenormalan, uji multikolinearitas, uji heteroskedastisitas, dan uji autokorelasi, (5) analisis regresi data panel fixed effect model dengan penduga LSDV, (6) signifikasi parameter, (7) uji perbandingan, dan (8) interpretasi model.

\section{Hasil dan Pembahasan}

Langkah awal yang dilakukan pada penelitian ini adalah menyebarkan kuesioner di PT PLN Gianyar kepada 25 orang tenaga kerja non-outsourcing dan 25 orang tenaga kerja outsourcing, dilanjutkan dengan melalukan uji validitas, reliabilitas, dan Confirmatory Factor Analysis (CFA)pada 
kuesioner tersebut. Kriteria uji yang digunakan untuk uji validitas adalah menggunakan nilai koefisien korelasi $(r)$, sedangkan uji reliabilitas menggunakan nilai koefisien Cronbach's Alpha $\geq 0,8$ (Marczyket al., 2005). Pengujian dilakukan dengan menganalisis setiap kelompok item pertanyaan berdasarkan tahun penelitian, yaitu 2010; 2011; dan 2012, sesuai dengan banyaknya variabel yang dilibatkan pada model penelitian, yaitu motivasi, existence yang dianalisis dengan item pertanyaan pada indikator gaji, lingkungan kerja, dan jaminan sosial;relatedness yang dianalisis dengan item pertanyaan pada indikator komunikasi, supervisi, dan kelompok; sertagrowth dianalisis dengan item pertanyaan pada indikator penghargaan, prestasi, dan tanggung jawab. Berdasarkan nilai koefisien korelasi (r)diperoleh bahwa setiap kelompok item pertanyaan telah valid. Nilai koefisien Cronbach's Alpha yang diperoleh untuk setiap kelompok item pertanyaan telah memenuhi syarat reliabilitas yang berarti apabila peneliti lain melakukan penelitian pada waktu dan objek yang sama, maka hasil yang diperoleh akan sama atau apabila peneliti yang sama melakukan penelitian dalam waktu yang berbeda, maka akan menghasilkan data yang sama.

Tahap selanjutnya adalah CFA. Pengujian CFA dilakukan dengan menggunakan uji Kaiser Meyer Olkin (KMO) > 0,5, uji Bartlett's $<\alpha(0,05)$ (Hair et al., 2010), dan Measure of Sampling Adequacy (MSA) $\geq 0,5$ (Hair et al., 2010) untuk setiap kelompok item pertanyaan berdasarkan tahun penelitian sesuai dengan variable motivasi, existence, relatedness, dan growth. Ada beberapa kriteria pada nilai MSA, yaitu MSA $=1$ berarti variabel dapat diprediksi secara sempurna tanpa kesalahan oleh variabel lain; MSA > 0,5 berarti variabel masih dapat diprediksi dan bisa dianalisis lagi; MSA $<0,5$ berarti variabel tidak dapat diprediksi dan dihilangkan dari analisis. Hasil pengujian ini menunjukkan bahwa semua kelompok item pertanyaan telah memenuhi kriteria pengujian CFA dan menghasilkan empat faktor baru sesuai dengan pengelompokkan item pertanyaan yang telah ditentukan, yaitu existence, relatedness, dan growth.

Pengujian CFA menghasilkan empat faktor baru yang digunakan dalam penelitian ini. Keempat faktor ini akan memasuki tahapan baru yaitu uji asumsi klasik pada model non-outsourcing dan outsourcing yang meliputi uji kenormalan dengan menggunakan uji Jarque-Bera, uji multikolinearitas dengan menggunakan matriks korelasi dan nilai VIF, uji heteroskedastisitas dengan menggunakan uji Breusch-Pagan-Godfrey (BPG), dan uji autokorelasi dengan menggunakan uji Durbin-Watson. Berdasarkan hasil pengujian diperoleh bahwa model non-outsourcing dan outsourcing telah memenuhi uji kenormalan, sedangkan uji multikolinearitas belum terpenuhi untuk kedua model. Salah satu cara yang bisa digunakan untuk mengatasi multikolinearitas adalah mengeleminasi variabel bebas yang memiliki nilai $V I F \geq 4$ (O’Brien, 2007).

Berdasarkan hasil penelitian pada model non-outsourcing diperoleh bahwa relatedness dan growth memiliki nilai $V I F \geq 4$, sehingga kedua variabel ini dikeluarkan dari model. Pada model outsourcing diperoleh bahwa relatedness memiliki nilai $V I F \geq 4$, sehingga relatedness dikeluarkan dari model. Selanjutnya dilakukan kembali uji asumsi klasik, yaitu uji kenormalan, multikolinearitas, heteroskedastisitas, dan autokorelasi. Hasil pengujian ini diperoleh bahwa kedua model telah memenuhi uji asumsi klasik, yaitu residual data berdistribusi normal, tidak terjadi multikolinearitas antara variabel bebas yang diujikan, serta tidak terjadi heteroskedastisitas dan autokorelasi pada kedua model, sehingga bisa dilanjutkan dengan analisis regresi data panel.

Berdasarkan analisis regresi data panel melalui pendekatan FEM dengan penduga LSDV, diperoleh dua model non-outsourcing dan outsourcing, yaitu: 


$$
\begin{gathered}
\text { Mot }_{\text {non }_{\text {it }}}=-0,05+0,56 E X_{i t} \\
\text { Mot }_{\text {out }_{\text {it }}}=0,21-0,00 E X_{i t}+0,85 G R_{i t}
\end{gathered}
$$

Nilai intersep yang dihasilkan pada regresi data panel melalui pendekatan FEM dengan penduga LSDV, baik untuk model nonoutsourcing maupun model outsourcing, adalah berbeda-beda untuk masing-masing responden, sedangkan nilai slope tetap sama. Hal ini membuktikan bahwa asumsi yang digunakan untuk FEM, yaitu intersep $\alpha_{i}$ berbeda antarindividu, tetapi slope $\beta$ tetap sama antarindividu dan antarwaktu telah terpenuhi. Perbedaan nilai intersep menunjukkan bahwa setiap unit/individu mempunyai nilai motivasi yang berbeda-beda dan nilai slope menunjukkan besarnya pengaruh existence terhadap motivasi pada tenaga kerja non-outsourcing serta besarnya pengaruh existence dan growth terhadap motivasi pada tenaga kerja outsourcing di PT PLN Gianyar. Berikut ini adalah interpretasi untuk masing-masing model yaitu:

1. Model non-outsourcing menunjukkan bahwa ketika tidak ada existence, maka motivasi tenaga kerja non-outsourcing akan menurun sebesar 0,05 satuan. Selain itu dapat disimpulkan juga bahwa ketika existence tenaga kerja non-outsourcing diakui sebesar satu satuan maka secara rata-rata motivasi tenaga kerja akan meningkat sebesar 0,56 satuan. Artinya setiap meningkatnya pengakuan terhadap tenaga kerja non-outsourcing, maka motivasinya akan meningkat sebesar 0,56 satuan.

2. Model outsourcing menunjukkan ketika tidak ada existence dan growth, maka motivasi tenaga kerja outsourcing meningkat sebesar 0,21 satuan. Selain itu juga dapat ditarik kesimpulan bahwa ketika existence (keberadaan) tenaga kerja outsourcing diakui sebesar 1 satuan, maka secara rata-rata motivasi tenaga kerja tersebut akan menurun sebesar 0,00 satuan, yang artinya pengakuan terhadap tenaga kerja outsourcing tidak memiliki pengaruh terhadap motivasi tenaga kerja tersebut serta ketika growth (pertumbuhan) tenaga kerja outsourcing berkembang sebesar 1 satuan, maka secara rata-rata motivasi tenaga kerja akan meningkat sebesar 0,85 satuan. Artinya setiap berkembangnya potensi diri tenaga kerja non-outsourcing sebesar 1 satuan, maka motivasinya akan meningkat sebesar 0,85 satuan.

Lebih lanjut lagi dilakukan pengujian signifikansi parameter pada kedua model. Pada uji simultan model non-outsourcing diperoleh $F$-hitung $>F_{(24,49 ; 0,05)}$, yaitu 4,12> 1,74 , sehingga terdapat minimal satu parameter yang memuat variabel bebas yang berpengaruh terhadap variabel respon. Tabel 2 menunjukkan hasil uji parsial model nonoutsourcing diperoleh $t$-statistik $>t_{(0,025 ; 49)}$ (2,01)untuk variabel existenceyaitu 6,43 > 2,01, sehingga dapat disimpulkan existence berpengaruh signifikan pada motivasinonoutsourcing.

Tabel 2.Uji Parsial Model Motivasi Non-outsourcing

\begin{tabular}{crrrr} 
Variable & Coefficient & Std. Error & t-Statistic & Prob. \\
\hline \hline C & -0.056253 & 0.063054 & -0.892134 & 0.3767 \\
EX? & 0.565053 & 0.087836 & 6.433014 & 0.0000
\end{tabular}

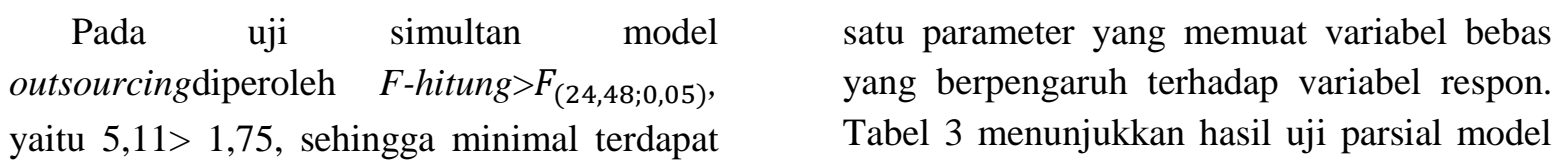


outsourcingdengant-statistik $>t_{(0,025 ; 48)}(2,01)$ untuk masing-masing variabel bebas yaitu untuk variabel existence diperoleh $|-0,05|<$ 2,01 dan untuk variabel growth diperoleh 6,40
> 2,01, sehingga dapat disimpulkan existence tidak berpengaruh secara signifikan sedangkan growth berpengaruh signifikan pada motivasi outsourcing.

Tabel 3.Uji Parsial Model Motivasi Kerja Outsourcing

\begin{tabular}{crrrr} 
Variable & Coefficient & Std. Error & t-Statistic & Prob. \\
\hline \hline C & 0.213898 & 0.092392 & 2.315116 & 0.0249 \\
EX? & -0.007668 & 0.135104 & -0.056758 & 0.9550 \\
GR? & 0.854690 & 0.133470 & 6.403628 & 0.0000
\end{tabular}

Existence berpengaruh signifikan pada model non-outsourcing serta existence tidak berpengaruh secara signifikandan growth berpengaruh signifikan pada model outsourcing dengan nilai koefisien determinasi $R^{2}$ yang dimiliki untuk masingmasing model yaitu $R^{2}$ untuk model nonoutsourcing sebesar 0,67 yang berarti $67 \%$ motivasi tenaga kerja non-outsourcing dijelaskan oleh existence dan $R^{2}$ untuk model outsourcingsebesar 0,73 yang berarti $73 \%$ motivasi tenaga kerja outsourcing dijelaskan oleh existence dan growth.

Hasil pengujian terhadap tenaga kerja non-outsourcing dan outsourcing didapatkan bahwa tidak ada variabel bebas yang memiliki pengaruh signifikansi yang sama pada kedua model. Pada model non-outsourcing, existence berpengaruh secara signifikan terhadap motivasi tenaga kerja nonoutsourcing, sedangkan pada model outsourcing, existence tidak berpengaruh secara signifikan terhadap motivasi tenaga kerja outsourcing. Berdasarkan hasil regresi data panel tersebut, uji perbandingan tidak dapat dilanjutkan.

\section{Kesimpulan}

Berdasarkan hasil pembahasan dapat ditarik beberapa kesimpulan sebagai berikut:

1. Model regresi data panel yang diperoleh untuk data motivasi tenaga kerja PT PLN Gianyar tahun 2010-2012 dengan pendekatan FEM adalah sebagai berikut:

$$
\begin{aligned}
& \text { a. Non-outsourcing } \\
& \text { Mot }_{\text {non }_{\text {it }}}=-0,05+0,56 E X_{i t}
\end{aligned}
$$

$$
\begin{array}{r}
\text { b. Outsourcing } \\
\text { Mot }_{\text {out }_{i t}}=0,21-0,00 E X_{i t} \\
+0,85 G R_{i t}
\end{array}
$$

2. Berdasarkan penelitian tentang motivasi tenaga kerja di PT PLN Gianyar, diperoleh bahwa existence (EX) berpengaruh positif dan signifikan terhadap motivasi tenaga kerja nonoutsourcing di PT PLN Gianyar dengan nilai $R^{2}$ non-outsourcing sebesar $67 \%$ yang berarti $67 \%$ motivasi tenaga kerja non-outsourcing dipengaruhi oleh existence sedangkan existence (EX) tidak berpengaruh secara signifikan dan growth (GR) berpengaruh positif dan signifikan terhadap motivasi tenaga kerja outsourcing di PT PLN Gianyar dengan nilai $R^{2}$ outsourcing sebesar $73 \%$ yang berarti $73 \%$ motivasi tenaga kerja outsourcing dipengaruhi oleh existence dan growth.

\section{DaftarPustaka}

Greene. W. H. 2012. Econometric Analysis. Seventh edition. New Jersey: Prentice Hall

Gujarati. 2004. Basic Econometrics. New York: McGraw-Hill

Hair JR. J. F., Black, W.C., Babin, B. J., and 
Anderson, R. E. 2010. Multivariate Data Analysis.Seventh edition. New Jersey: Pearson Prentice Hall.

Hsiao, C. 2003. Analysis of Panel Data. Second edition. New York: Cambrige University Press.

Tim Penyusun Pusat Bahasa. 2012. Kamus Besar Bahasa Indonesia Pusat Bahasa. Edisi Keempat. Jakarta: PT Gramedia Pustaka Utama.

Marczyk, G., DeMatteo, D., and Festinger, D.2005. Essentials of Research Design and Methodology. New Jersey: John WILEY \& sons, Inc.

O'Brien. R. M. 2007. A Caution Regarding Rules of Thumb for Variance Inflation Factor. Quality \& Quantity Journal. 41. 637-690. 